\title{
Patient Factors Associated with Pharmaceutical Interventions for Inpatients at a Brazilian Teaching Hospital
}

\author{
Debora Bernardes Francisco, Karine Dal Paz, and Thiago Vinicius Nadaleto Didone
}

Can J Hosp Pharm. 2021;74(3):211-8

DOI: 10.4212/cjhp.v74i3.3148

\begin{abstract}
Background: Pharmaceutical interventions aim to correct or prevent a drug-related problem (DRP) that might lead to negative clinical consequences and increase health care costs.

Objective: To identify variables associated with the provision of pharmaceutical interventions by clinical pharmacists during hospitalization.

Methods: In this retrospective cohort study, adult inpatients of the medical ward of the University Hospital of the University of São Paulo in São Paulo, Brazil, were followed from admission to discharge. Logistic regression models were used to evaluate the association between occurrence of at least 1 pharmaceutical intervention and the following baseline characteristics: sex, age, Charlson comorbidity index, renal failure, electrolyte imbalance, hemoglobin, platelet count, and use of a nasoenteric tube, as well as the number, second-level Anatomical Therapeutic Chemical (ATC) code, and administration route of prescribed medications.
\end{abstract}

Results: A total of 148 patients were included in the study, of whom $75(50.7 \%)$ were men. The mean age was 62.8 (95\% confidence interval [CI] 59.9-65.8) years, and the mean length of the hospital stay was 10.7 (95\% Cl 8.4-13.1) days. Analgesics (ATC code N02), the most common type of medication, were prescribed to 144 (97.3\%) of the patients. Pharmaceutical interventions were performed for only $49(33.1 \%)$ of the patients. One out of every 4 of these interventions was intended to obtain information not provided in the prescription, to allow the prescription to be completed and dispensing to proceed. According to the multivariate analysis, the odds ratio (OR) of occurrence of at least 1 pharmaceutical intervention increased for patients with electrolyte imbalance (OR 2.68,95\% Cl 1.09-6.63; $p=0.033$ ), patients using 5 to 8 medications (OR $8.73,95 \% \mathrm{Cl} 1.07-71.36 ; p=0.043$ ), patients using 9 or more medications (OR 10.39, 95\% Cl 1.28-84.05; $p=0.028$ ), and patients using at least 1 systemic antibacterial (ATC code J01; OR 2.76, $95 \% \mathrm{Cl} 1.30-5.84 ; p=0.008$ ).

Conclusions: The findings of this study could allow the identification, at the time of admission and possibly before the occurrence of a DRP, of patients at higher risk of requiring a pharmaceutical intervention later during their hospital stay. To optimize patient care, clinical pharmacists should closely follow inpatients with electrolyte imbalance, polypharmacy, and/or use of systemic antibacterials.

Keywords: anti-infective agents, drug-related side effects, adverse reactions, patient safety, medication therapy management, pharmaceutical services

\begin{abstract}
RÉSUMÉ
Contexte : Les interventions pharmaceutiques visent à corriger ou à prévenir un problème lié aux drogues (PLD), qui pourrait entraîner des conséquences cliniques négatives et accroître les coûts des soins de santé.

Objectif : Déterminer les variables associées aux interventions pharmaceutiques des pharmaciens cliniques lors d'une hospitalisation.

Méthodes : Dans cette étude de cohorte rétrospective, les patients adultes hospitalisés au Service de médecine de I'Hôpital universitaire de São Paulo au Brésil ont été suivis dès leur admission et jusqu'à leur sortie. Des modèles de régression logistique ont été utilisés pour évaluer l'association entre au moins une intervention pharmaceutique et les caractéristiques de base suivantes: sexe, âge, indice de comorbidité de Charlson, insuffisance rénale, déséquilibre électrolytique, hémoglobine, numération plaquettaire et utilisation d'un tube nasoentérique, et l'ensemble du groupe a subi une évaluation selon le nombre de médicaments prescrits au deuxième niveau des classifications du Système de classification anatomique thérapeutique chimique (ATC) et leur voie d'administration.
\end{abstract}

Résultats : Cent-quarante-huit (148) patients ont été inclus dans cette étude; 75 d'entre eux (50,7 \%) étaient des hommes. L'âge moyen était de 62,8 ans (95\% intervalle de confiance [IC] 59,9 - 65,8), et la durée moyenne du séjour à l'hôpital était de 10,7 jours (95\% IC 8,4 - 13,1). Des analgésiques (code ATC N02), type de médicament le plus répandu, ont été prescrits à 144 patients (97,3\%). Seuls 49 patients $(33,1 \%)$ ont fait l'objet d'une intervention pharmaceutique. Une de ces interventions sur quatre avait pour but d'obtenir des informations absentes dans la prescription mais indispensables à l'obtention de la validation de la prescription et de l'autorisation de distribution des médicaments. Selon l'analyse multivariée, le rapport de cotes (RC) de la nécessité d'au moins une intervention pharmaceutique augmentait pour les patients ayant un déséquilibre électrolytique (RC 2,68, $95 \%$ IC 1,09-6,63; $p=0,033$ ), les patients prenant entre cinq et huit médicaments (RC 8,73, $95 \%$ IC 1,07 71,$36 ; p=0,043$ ), les patients prenant au moins neuf médicaments (RC 10,39, $95 \%$ IC 1,28 - 84,05; $p=0,028$ ) et ceux utilisant au moins un antibactérien systémique (code ATC J01; RC 2,76, $95 \%$ IC 1,30-5,84; $p=0,008$ ).

Conclusions : Les résultats de cette étude pourraient permettre d'identifier, à l'admission à I'hôpital et probablement avant l'apparition d'un PLD, les patients présentant des risques plus élevés, qui pourraient nécessiter une intervention pharmaceutique plus tard lors de leur séjour. Pour optimiser les soins aux patients, les pharmaciens cliniques doivent suivre étroitement les patients hospitalisés ayant un déséquilibre électrolytique, ceux qui nécessitent une polypharmacie et ceux qui utilisent des antibactériens systémiques.

Mots-clés : agents anti-infectieux, effets secondaires liés aux drogues, effets indésirables, sécurité du patient, gestion de la pharmacopée, services pharmaceutiques 


\section{INTRODUCTION}

A pharmaceutical intervention is defined as an action that could be taken at the prescriber, patient, or medication-use level, aimed at preventing or correcting a drug-related problem (DRP) and thus contributing to the optimization of pharmacotherapy outcomes. ${ }^{1}$ DRPs are events involving drug therapy with the potential to negatively affect the desired health outcome. ${ }^{2}$ This definition encompasses medication errors, adverse drug reactions, and adverse drug events (ADEs). ${ }^{3}$

The negative effects of DRPs on health outcomes have been previously reported. For example, a meta-analysis showed that $10 \%$ of hospital admissions among older adults were due to adverse drug reactions. ${ }^{4}$ A German prospective observational study reported that $16.2 \%$ of hospital admissions were related to 1 or more community-acquired ADEs. ${ }^{5}$ Furthermore, older adults with ADEs during hospitalization had $25 \%$ and $9 \%$ higher odds of readmission and in-hospital mortality, respectively, relative to those without ADEs. Hospitalization with an ADE was associated with a 2.2-day increase in length of stay, at an additional cost of US $\$ 3782 .{ }^{6}$ In the United Kingdom, it has been estimated that medication errors cause 12000 deaths per year, contributing to an additional $£ 0.75$ billion to $£ 1.5$ billion in health care expenditures. ${ }^{7}$ A systematic review, including studies conducted in primary care and hospital settings, found mean costs per medication error ranging from $€ 2.58$ to $€ 111727.08$. $^{8}$

DRPs may be due to factors such as previous or current diseases, decreased renal function, advanced age, sex, body weight and fat distribution, allergy history, and genetic predisposition. ${ }^{4,9,10}$ They can also be related to social factors such as alcohol drinking, race or ethnicity, and smoking. ${ }^{10}$ In addition, there are some drug-related factors that could increase the risk of a DRP, such as the IV route of drug administration, the use of 5 or more medications, and drug dose and frequency. ${ }^{9,10}$ Predicting the risks of ADEs can facilitate pharmacovigilance and targeted interventions for high-risk inpatients by the multidisciplinary health care team. ${ }^{11,12}$ Interventions to reduce medication errors and improve the quality of care in the health sector are required to increase effectiveness from both clinical and cost perspectives. ${ }^{8}$

Given that DRPs can substantially affect the health care system, there is a clear need for their prevention in clinical practice. ${ }^{13}$ Accordingly, pharmaceutical strategies to prevent DRPs include the identification and reporting of medication errors and adverse drug reactions, monitoring of drug interactions, dose individualization for patients with renal or hepatic dysfunction, and the investigation of IV compatibility and dilution stability of drugs. ${ }^{14}$

Given the clinical and economic impacts of DRPs, the aim of this study was to identify patient characteristics associated with the occurrence of at least 1 pharmaceutical intervention during the hospital stay.

\section{METHODS}

A retrospective cohort study was carried out using data for inpatients of the medical ward of the University Hospital of the University of São Paulo, a 196-bed secondary level public teaching hospital in São Paulo, Brazil, that offers medium-complexity clinical services to students and staff, as well as to the local community. The medical ward has 38 beds and a clinical staff of 6 physicians, 13 nurses, and 2 clinical pharmacists, namely 1 clinical pharmacology specialist, who is responsible for the ward and mentorship of the residency program, and 1 resident pharmacist. In this ward, the clinical pharmacists perform thorough follow-up of all inpatients, from admission to discharge. The hospital's pharmacy team is responsible for preventing, identifying, and resolving DRPs through the design and implementation of pharmaceutical interventions, which are documented in a pharmacy database on a daily basis. The main activities of this team include medication reconciliation, assessment of patients' needs and the effectiveness and safety of drug therapy, screening of medical prescriptions, evaluation of drug interactions and physicochemical compatibility, determination of the adequacy of pharmaceutical forms, monitoring of serum levels of drugs, participation in medical rounds, pharmacovigilance, discharge guidance, and assistance to the multidisciplinary team.

Patients aged 18 years or older who were admitted to the medical ward from October 1 to November 30, 2018, and not released within the first 24 hours, were included in this study. Patients receiving palliative care, those who died, and those who were transferred before occurrence of the first pharmaceutical intervention were excluded. Prescribed medications and clinical and laboratory data recorded in the first 24 hours of admission (baseline) were collected from each patient's medical record (hard copy) by one of the authors (D.B.F.). All pharmaceutical interventions performed during the hospitalization period, and the corresponding acceptance ratio (rate rate at which recommendations for a pharmaceutical intervention were accepted by the health care team), were obtained from the pharmacy database (Excel, Microsoft Corporation). Information about pharmaceutical interventions was paired with patient characteristics by means of each patient's identification number.

Data for the study, which were limited to patients' characteristics, were collected using a form designed specifically for this purpose. The following definitions were used. Renal failure was defined as creatinine clearance less than $30 \mathrm{~mL} / \mathrm{min} / 1.73 \mathrm{~m}^{2}$, as estimated by the Chronic Kidney Disease Epidemiology Collaboration formula. ${ }^{15}$ Electrolyte imbalance was defined as at least one of the following: 
hyponatremia $\left(\mathrm{Na}^{2+}<136 \mathrm{mEq} / \mathrm{L}\right)$, hypernatremia $\left(\mathrm{Na}^{2+}\right.$ $>145 \mathrm{mEq} / \mathrm{L})$, hypokalemia $\left(\mathrm{K}^{+}<3.5 \mathrm{mEq} / \mathrm{L}\right)$, or hyperkalemia $\left(\mathrm{K}^{+}>5.1 \mathrm{mEq} / \mathrm{L}\right)$. Hemoglobin reference values were 13.5 to $17.5 \mathrm{~g} / \mathrm{dL}$ (135 to $175 \mathrm{~g} / \mathrm{L}$ ) for men and 12.0 to $16.0 \mathrm{~g} / \mathrm{dL}$ (120 to $160 \mathrm{~g} / \mathrm{L}$ ) for women. For platelet count, the reference value was 150000 to $400000 / \mu \mathrm{L}$ (140 to 400 $\left.\times 10^{9} / \mathrm{L}\right)$.

Medications were categorized according to secondlevel codes of the Anatomical Therapeutic Chemical (ATC) classification system ${ }^{16}$; patients were then dichotomized as users or non-users of medications defined by each code. Only the most frequently prescribed ATC codes were used to calculate the regression models.

Each pharmaceutical intervention was designed to resolve or correct one or more DRPs, and these interventions were categorized according to the DRP they were most likely intended to resolve. The Pharmaceutical Care Network Europe (PCNE) classification scheme for DRP causes (version 9.00) was used for this purpose. ${ }^{2}$ Characteristics not related to patients that might also affect the occurrence of a pharmaceutical intervention, such as factors related to the pharmacists performing the intervention, were not collected or evaluated.

Statistical analyses were carried out using SPSS software, version 22.0 (IBM Corporation). Categorical data were described as absolute and relative counts. Seventeen logistic regression models were calculated to estimate the dependent variable, which was the occurrence of at least 1 pharmaceutical intervention during the hospitalization period (as a dichotomous variable, relative to the absence of such an intervention). The independent variables were sex (male, female); age ( $<65$ years, $\geq 65$ years); Charlson comorbidity index ${ }^{17}(0-3, \geq 4)$; renal failure (no, yes); electrolyte imbalance (no, yes); hemoglobin (within reference range, altered); platelet count (within reference range, altered); use of nasoenteric feeding tube (no, yes); number of prescribed medications $(<5,5-8, \geq 9)$; medications from ATC codes B01 (non-user, user), A03 (non-user, user), A10 (non-user, user), A04 (non-user, user), C10 (non-user, user), and J01 (non-user, user); and use of at least 1 IV medication (no, yes). Variables with $p$ values less than 0.10 in univariate models were included in the multivariate analysis in a single block. Pairs of variables were checked for associations by means of $\chi^{2}$ tests before the multivariate analyses were run, to avoid collinearity; out of 2 significantly associated variables, only the variable with the most clinical and conceptual relevance was included in the analysis. The level of significance was set at $\alpha=5 \%, p<0.05$.

Regarding the number of prescribed medications, we obtained the most effective cut-off point to distinguish between admissions with and without a pharmaceutical intervention by analysis of the receiver operating characteristic curve. Since the most effective cut-off was a considerably low value, we created another cut-off using the median of the remaining higher values. Medians of age and Charlson comorbidity index were used to dichotomize these values, because the $p$ values related to area under the receiver operating characteristic curve were not significant.

Post hoc analyses were performed to verify the association between the variables retained in the multivariate regression model and the types of pharmaceutical intervention, by means of likelihood ratio $\chi^{2}$ tests. Since each PCNE code is encompassed in a primary domain, we considered these as the pharmaceutical intervention types.

The research ethics committees of the University Hospital (ID 3422497) and the School of Pharmaceutical Sciences (ID 3358233) of the University of São Paulo approved this retrospective study. These committees waived the need for informed consent from patients.

\section{RESULTS}

Overall, 153 patients were eligible for the study, of whom 5 (3.3\%) were excluded because they died before a pharmaceutical intervention occurred. The analyses therefore included 148 patients, with 128 (86.5\%) referred from primary care and $20(13.5 \%)$ admitted in the emergency unit. The mean age was 62.8 (95\% confidence interval [CI] 59.9$65.8)$ years, and 75 patients $(50.7 \%)$ were men. Half of the patients $(n=74)$ were 65 years of age or older. The hospitalization period ranged from 1 to 102 days, with a mean of 10.7 (95\% CI 8.4-13.1) days.

Pharmacists proposed a total of 124 pharmaceutical interventions for 49 (33.1\%) of the patients (Table 1). A total of $120(96.8 \%)$ of these interventions were accepted by the medical team. Twenty (40.8\%) patients had 1 intervention, 15 (30.6\%) had 2 interventions, and 14 (28.6\%) had 3 or more interventions. The most common interventions were intended to resolve DRPs related to the logistics of the prescribing and dispensing process. Of note, 1 of every 4 pharmaceutical interventions was intended to obtain information not provided in the prescription, to allow the prescription to be completed and dispensing to proceed.

Of the 40 second-level ATC codes identified, analgesics (N02) were the most frequently prescribed $(97.3 \%$ of patients), followed by antithrombotics (B01; 68.2\%) and drugs for functional gastrointestinal disorders (A03; 52.7\%) (Table 2).

Both univariate and multivariate analysis (Table 3) revealed 3 patient characteristics at the time of admission that increased the odds of at least 1 pharmaceutical intervention during the hospital admission: presence of electrolyte imbalance, more than 4 prescribed medications, and prescription of at least 1 antibacterial for systemic use (ATC code J01).

Given that almost every patient had a prescription for a medication with ATC code N02 (analgesics), mainly represented by non-opioid analgesics such as dipyrone, this 
TABLE 1. Reasons for Pharmaceutical Interventions

during Hospital Admission, According to PCNE

Classification Scheme of DRP Causes (version 9.00), ${ }^{2}$

Grouped by Primary Domain

\begin{tabular}{|c|c|c|}
\hline \multirow{2}{*}{$\begin{array}{l}\text { Primary Domain and Reason for Intervention } \\
\text { Dispensing }\end{array}$} & \multicolumn{2}{|c|}{$\begin{array}{c}\text { No. }(\%) \text { of } \\
\text { Interventions } \\
(n=124)\end{array}$} \\
\hline & & \\
\hline Necessary information not provided & 31 & $(25.0)$ \\
\hline Prescribed drug not available & 8 & $(6.5)$ \\
\hline \multicolumn{3}{|l|}{ Dose selection } \\
\hline Drug dose too high & 17 & $(13.7)$ \\
\hline Dosage regimen too frequent & 7 & $(5.6)$ \\
\hline Drug dose too low & 6 & $(4.8)$ \\
\hline Dosage regimen not frequent enough & 3 & $(2.4)$ \\
\hline $\begin{array}{l}\text { Instructions for dose timing wrong, unclear, } \\
\text { or missing }\end{array}$ & 1 & $(0.8)$ \\
\hline \multicolumn{3}{|l|}{ Drug selection } \\
\hline $\begin{array}{l}\text { No or incomplete drug treatment in spite } \\
\text { of existing indication }\end{array}$ & 14 & $(11.3)$ \\
\hline No indication for drug & 8 & $(6.5)$ \\
\hline $\begin{array}{l}\text { Inappropriate drug according to guidelines } \\
\text { or formulary }\end{array}$ & 2 & $(1.6)$ \\
\hline Too many drugs prescribed for indication & 1 & $(0.8)$ \\
\hline \multicolumn{3}{|l|}{ Drug form } \\
\hline Inappropriate drug form & 12 & $(9.7)$ \\
\hline \multicolumn{3}{|l|}{ Drug-use process } \\
\hline $\begin{array}{l}\text { Inappropriate timing of administration or } \\
\text { dosing intervals }\end{array}$ & 10 & $(8.1)$ \\
\hline \multicolumn{3}{|l|}{ Other } \\
\hline No or inappropriate outcome monitoring & 3 & $(2.4)$ \\
\hline \multicolumn{3}{|l|}{ Patient transfer-related } \\
\hline No medication reconciliation at transfer & 1 & $(0.8)$ \\
\hline
\end{tabular}

DRP $=$ drug-related problem, $\mathrm{PCNE}=$ Pharmaceutical Care Network Europe.

variable was not considered for the regression analysis. The ATC code C10 (lipid-modifying agents) was not included in model 17 (multivariate) because it was associated with ATC code J01 (antibacterials for systemic use, $p=0.004$ ).

Post hoc analyses revealed that the types of pharmaceutical intervention (as primary domains) were evenly distributed across the categories for electrolyte imbalance $(p=0.18)$, number of prescribed medications $(p=0.35)$, and antibacterials for systemic use $(p=0.053)$. The primary domains are listed in Table 1.

\section{DISCUSSION}

In this study, we identified several characteristics of patients that might contribute to the occurrence of a pharmaceutical intervention. Given that such interventions are intended to correct or prevent DRPs, this finding may allow identification of patients at increased risk of DRPs. Hence, the
TABLE 2. Frequency of Medications Prescribed at Baseline, Categorized by Second-Level ATC Codes

\begin{tabular}{|c|c|c|c|}
\hline \multirow{2}{*}{$\begin{array}{l}\text { ATC Category } \\
\text { Analgesics }\end{array}$} & \multirow{2}{*}{$\begin{array}{c}\begin{array}{c}\text { ATC } \\
\text { Code }\end{array} \\
\text { N02 }\end{array}$} & \multicolumn{2}{|c|}{$\begin{array}{c}\text { No. }(\%) \\
\text { of Patient } \\
(n=148)\end{array}$} \\
\hline & & 144 & $(97.3)$ \\
\hline Antithrombotic agents & B01 & 101 & (68.2) \\
\hline Drugs for functional gastrointestinal disorders & $\mathrm{A} 03$ & 78 & $(52.7)$ \\
\hline Drugs used in diabetes & $\mathrm{A} 10$ & 66 & $(44.6)$ \\
\hline Antiemetics and antinauseants & $\mathrm{A} 04$ & 58 & (39.2) \\
\hline Lipid-modifying agents & C10 & 58 & (39.2) \\
\hline Antibacterials for systemic use & J01 & 57 & $(38.5)$ \\
\hline Drugs for acid-related disorders & $\mathrm{A} 02$ & 56 & $(37.8)$ \\
\hline Diuretics & $\mathrm{CO3}$ & 46 & $(31.1)$ \\
\hline$\beta$-Blocking agents & $\mathrm{CO7}$ & 39 & $(26.4)$ \\
\hline $\begin{array}{l}\text { Agents acting on the renin-angiotensin } \\
\text { system }\end{array}$ & Co9 & 37 & $(25.0)$ \\
\hline Psycholeptics & N05 & 30 & $(20.3)$ \\
\hline Drugs for obstructive airway diseases & R03 & 22 & $(14.9)$ \\
\hline Cardiac therapy & $\mathrm{C} 01$ & 22 & $(14.9)$ \\
\hline Vitamins & A11 & 22 & $(14.9)$ \\
\hline Corticosteroids for systemic use & $\mathrm{H} 02$ & 21 & $(14.2)$ \\
\hline Drugs for constipation & $\mathrm{A} 06$ & 20 & $(13.5)$ \\
\hline Antiepileptics & N03 & 20 & $(13.5)$ \\
\hline Antihypertensives & $\mathrm{CO2}$ & 14 & (9.5) \\
\hline Calcium-channel blockers & $\mathrm{C} 08$ & 13 & (8.8) \\
\hline Thyroid therapy & $\mathrm{HO3}$ & 13 & (8.8) \\
\hline Psychoanaleptics & N06 & 12 & $(8.1)$ \\
\hline Antianemic preparations & B03 & 10 & (6.8) \\
\hline Other nervous system drugs & N07 & 10 & (6.8) \\
\hline Antihistamines for systemic use & R06 & 10 & (6.8) \\
\hline Blood substitutes and perfusion solutions & B05 & 6 & $(4.1)$ \\
\hline Mineral supplements & $\mathrm{A} 12$ & 4 & (2.7) \\
\hline Urologicals & $\mathrm{G} 04$ & 3 & $(2.0)$ \\
\hline $\begin{array}{l}\text { Antidiarrheals, intestinal anti-inflammatory/ } \\
\text { anti-infective agents }\end{array}$ & $\mathrm{A} 07$ & 3 & $(2.0)$ \\
\hline Anthelmintics & P02 & 3 & (2.0) \\
\hline Antimycobacterials & J04 & 2 & (1.4) \\
\hline Antimycotics for systemic use & J02 & 2 & (1.4) \\
\hline Antiprotozoals & P01 & 2 & (1.4) \\
\hline All other therapeutic products & V03 & 2 & (1.4) \\
\hline Anti-parkinson drugs & N04 & 1 & $(0.7)$ \\
\hline Antihemorrhagics & B02 & 1 & $(0.7)$ \\
\hline $\begin{array}{l}\text { Anti-inflammatory and antirheumatic } \\
\text { products }\end{array}$ & M01 & 1 & $(0.7)$ \\
\hline Muscle relaxants & M03 & 1 & $(0.7)$ \\
\hline Antigout preparations & M04 & 1 & $(0.7)$ \\
\hline Ophthalmologicals & S01 & 1 & $(0.7)$ \\
\hline
\end{tabular}

ATC $=$ Anatomical Therapeutic Chemical classification. ${ }^{16}$ 
TABLE 3 (Part 1 of 2). Univariate and Multivariate Logistic Regression Models Estimating the Occurrence of $\geq 1$ Pharmaceutical Intervention (PI) during Hospital Admission

\begin{tabular}{|c|c|c|c|c|c|c|c|}
\hline \multirow[b]{2}{*}{ Model No., Variable, and Category } & \multicolumn{4}{|c|}{ No. $(\%)$ of Patients } & \multirow{2}{*}{\multicolumn{2}{|c|}{ OR $(95 \% \mathrm{Cl})$}} & \multirow[b]{2}{*}{$p$ Value } \\
\hline & \multicolumn{2}{|c|}{$\begin{array}{l}\text { Without PI } \\
(n=99)\end{array}$} & \multicolumn{2}{|c|}{$\begin{array}{l}\text { With PI } \\
(n=49)\end{array}$} & & & \\
\hline \multicolumn{8}{|l|}{ Univariate } \\
\hline \multicolumn{8}{|l|}{ 1: Sex } \\
\hline Male & 49 & $(49.5)$ & 26 & $(53.1)$ & 1.00 & (reference) & \\
\hline Female & 50 & $(50.5)$ & 23 & $(46.9)$ & 0.87 & $(0.44-1.72)$ & 0.68 \\
\hline \multicolumn{8}{|l|}{ 2: Age (years) } \\
\hline$<65$ & 47 & $(47.5)$ & 27 & $(55.1)$ & 1.00 & (reference) & \\
\hline$\geq 65$ & 52 & $(52.5)$ & 22 & $(44.9)$ & 0.74 & $(0.37-1.46)$ & 0.38 \\
\hline \multicolumn{8}{|l|}{ 3: Charlson comorbidity index } \\
\hline $0-3$ & 52 & $(52.5)$ & 23 & $(46.9)$ & 1.00 & (reference) & \\
\hline$\geq 4$ & 47 & $(47.5)$ & 26 & $(53.1)$ & 1.25 & $(0.63-2.48)$ & 0.52 \\
\hline \multicolumn{8}{|l|}{ 4: Renal failure } \\
\hline No & 73 & $(73.7)$ & 35 & $(71.4)$ & 1.00 & (reference) & \\
\hline Yes $^{\mathrm{a}}$ & 26 & $(26.3)$ & 14 & $(28.6)$ & 1.12 & $(0.52-2.41)$ & 0.77 \\
\hline \multicolumn{8}{|l|}{ 5: Electrolyte imbalance } \\
\hline No & 85 & (85.9) & 35 & (71.4) & 1.00 & (reference) & \\
\hline$Y_{e s}^{b}$ & 14 & $(14.1)$ & 14 & $(28.6)$ & 2.43 & $(1.05-5.62)$ & 0.038 \\
\hline \multicolumn{8}{|l|}{ 6: Hemoglobin $(n=124)$} \\
\hline Within reference range ${ }^{c}$ & 51 & $(61.4)$ & 20 & $(48.8)$ & 1.00 & (reference) & \\
\hline Altered & 32 & $(38.6)$ & 21 & $(51.2)$ & 1.67 & $(0.79-3.56)$ & 0.18 \\
\hline \multicolumn{8}{|l|}{ 7: Platelet count $(n=124)$} \\
\hline Within reference range ${ }^{d}$ & 63 & $(75.9)$ & 31 & $(75.6)$ & 1.00 & (reference) & \\
\hline Altered & 20 & $(24.1)$ & 10 & $(24.4)$ & 1.02 & $(0.43-2.43)$ & 0.97 \\
\hline \multicolumn{8}{|l|}{ 8: Nasoenteric tube } \\
\hline No & 95 & $(96.0)$ & 44 & $(89.8)$ & 1.00 & (reference) & \\
\hline Yes & 4 & $(4.0)$ & 5 & $(10.2)$ & 2.70 & $(0.69-10.54)$ & 0.15 \\
\hline \multicolumn{8}{|l|}{ 9: No. of medications } \\
\hline$<5$ & 18 & $(18.2)$ & 1 & $(2.0)$ & 1.00 & (reference) & \\
\hline $5-8$ & 41 & $(41.4)$ & 21 & $(42.9)$ & 9.22 & $(1.15-73.89)$ & 0.036 \\
\hline$\geq 9$ & 40 & $(40.4)$ & 27 & $(55.1)$ & 12.15 & $(1.53-96.48)$ & 0.018 \\
\hline \multicolumn{8}{|l|}{ 10: ATC code B01 } \\
\hline Non-user & 35 & $(35.4)$ & 12 & $(24.5)$ & 1.00 & (reference) & \\
\hline User & 64 & $(64.6)$ & 37 & $(75.5)$ & 1.69 & $(0.78-3.64)$ & 0.18 \\
\hline \multicolumn{8}{|l|}{ 11: ATC code A03 } \\
\hline Non-user & 44 & $(44.4)$ & 26 & $(53.1)$ & 1.00 & (reference) & \\
\hline User & 55 & (55.6) & 23 & $(46.9)$ & 0.71 & $(0.36-1.41)$ & 0.32 \\
\hline \multicolumn{8}{|l|}{ 12: ATC code A10 } \\
\hline Non-user & 56 & $(56.6)$ & 26 & $(53.1)$ & 1.00 & (reference) & \\
\hline User & 43 & $(43.4)$ & 23 & $(46.9)$ & 1.15 & $(0.58-2.29)$ & 0.69 \\
\hline \multicolumn{8}{|l|}{ 13: ATC code A04 } \\
\hline Non-user & 63 & $(63.6)$ & 27 & $(55.1)$ & 1.00 & (reference) & \\
\hline User & 36 & $(36.4)$ & 22 & $(44.9)$ & 1.43 & $(0.71-2.86)$ & 0.32 \\
\hline \multicolumn{8}{|l|}{ 14: ATC code C10 } \\
\hline Non-user & 53 & (53.5) & 37 & $(75.5)$ & 1.00 & (reference) & \\
\hline User & 46 & $(46.5)$ & 12 & $(24.5)$ & 0.37 & $(0.17-0.80)$ & 0.011 \\
\hline
\end{tabular}


TABLE 3 (Part 2 of 2). Univariate and Multivariate Logistic Regression Models Estimating the Occurrence of $\geq 1$ Pharmaceutical Intervention (PI) during Hospital Admission

\begin{tabular}{|c|c|c|c|c|c|c|c|}
\hline \multirow[b]{2}{*}{ Model No., Variable, and Category } & \multicolumn{4}{|c|}{ No. $(\%)$ of Patients } & \multirow{2}{*}{\multicolumn{2}{|c|}{ OR $(95 \% \mathrm{CI})$}} & \multirow[b]{2}{*}{$p$ Value } \\
\hline & \multicolumn{2}{|c|}{$\begin{array}{l}\text { Without PI } \\
(n=99)\end{array}$} & \multicolumn{2}{|c|}{$\begin{array}{l}\text { With PI } \\
(n=49)\end{array}$} & & & \\
\hline \multicolumn{8}{|l|}{ 15: ATC code J01 } \\
\hline Non-user & 69 & $(69.7)$ & 22 & $(44.9)$ & 1.00 & (reference) & \\
\hline User & 30 & $(30.3)$ & 27 & $(55.1)$ & 2.82 & $(1.39-5.73)$ & 0.004 \\
\hline \multicolumn{8}{|l|}{ 16: IV administration } \\
\hline No & 36 & $(36.4)$ & 15 & $(30.6)$ & 1.00 & (reference) & \\
\hline Yes & 63 & $(63.6)$ & 34 & $(69.4)$ & 1.30 & $(0.62-2.70)$ & 0.49 \\
\hline \multicolumn{8}{|l|}{ 17: Multivariate } \\
\hline $\begin{array}{l}\text { Electrolyte imbalance, yest } \\
\text { No. of medications }\end{array}$ & \multicolumn{2}{|c|}{ NA } & \multicolumn{2}{|c|}{ NA } & 2.68 & $(1.09-6.63)$ & 0.033 \\
\hline $5-8$ & \multicolumn{2}{|c|}{ NA } & \multicolumn{2}{|c|}{ NA } & 8.73 & $(1.07-71.36)$ & 0.043 \\
\hline$\geq 9$ & \multicolumn{2}{|c|}{ NA } & \multicolumn{2}{|c|}{ NA } & 10.39 & $(1.28-84.05)$ & 0.028 \\
\hline ATC code J01, user & \multicolumn{2}{|c|}{ NA } & \multicolumn{2}{|c|}{ NA } & 2.76 & $(1.30-5.84)$ & 0.008 \\
\hline
\end{tabular}

$\mathrm{Cl}=$ confidence interval, $\mathrm{NA}=$ not applicable, $\mathrm{OR}=$ odds ratio, $\mathrm{B} 01=$ antithrombotic agents, $\mathrm{A} 03=$ drugs for functional gastrointestinal disorders, $\mathrm{A} 10=$ drugs used in diabetes, $\mathrm{A} 04=$ antiemetics/antinauseants, $\mathrm{C} 10=$ lipid-modifying agents, $\mathrm{J} 01$ = antibacterials for systemic use.

${ }^{a}$ Creatinine clearance $<30 \mathrm{~mL} / \mathrm{min} / 1.73 \mathrm{~m}^{2}$.

${ }^{\mathrm{b}} \mathrm{Na}^{2+}<136$ or $>145 \mathrm{mEq} / \mathrm{L}$ or $\mathrm{K}^{+}<3.5$ or $>5.1 \mathrm{mEq} / \mathrm{L}$.

'For men, 13.5-17.5 g/dL (135-175 g/L); for women, $12.0-16.0 \mathrm{~g} / \mathrm{dL}(120-160 \mathrm{~g} / \mathrm{L})$.

d $150000-400000 / \mu \mathrm{L}\left(150-400 \times 10^{9} / \mathrm{L}\right)$.

eHosmer-Lemeshow $p=0.425 ; R^{2}=0.191$ (Nagelkerke).

clinical pharmacy team could work preventively, instead of acting after a DRP occurs. Most of the current literature has used direct evidence of DRPs (e.g., documented adverse drug reaction) instead of indirect evidence such as pharmaceutical interventions, so the possibilities for comparison of our results with other studies were very limited.

The leading causes of pharmaceutical interventions in this study were related to prescribing errors, such as omission of essential prescribing information (e.g., route of administration) or prescribing of inappropriately high doses. In another study at a tertiary Brazilian hospital, the most common pharmaceutical interventions in the intermediate care unit were related to medication prescribed without indication (14.1\%), prescription adjustment (14.1\%), dose adjustment according to renal function (11.3\%), use of potentially inappropriate medications for elderly patients (7.5\%), dose adjustment when the initial dose was out of the therapeutic range (3.8\%), and inadequate use of antimicrobial agents (1.9\%). ${ }^{18}$ Because higher doses are common prescribing errors and contribute to the occurrence of DRPs, ${ }^{1,19,20}$ clinical pharmacists should pay special attention to the assessment of prescribed doses.

The medications most frequently prescribed in our study could reflect the high prevalence of cardiovascular and metabolic diseases among elderly patients. ${ }^{21}$ Other possible reasons could be the frequent need to treat inpatients' pain and physicians' prescribing preferences. Supporting evidence comes from a Brazilian study conducted on 5 different wards of a teaching hospital, which showed that the overall prevalence of pain was $31.8 \%$ and that the analgesic most often prescribed to treat it was dipyrone (76.1\%). ${ }^{22}$ Similar to our results, the major classes of medications prescribed at a Nigerian tertiary hospital were vitamins (82.9\%), antibiotics for systemic use (72.8\%), and analgesics (60.0\%). ${ }^{23}$

To the best of our knowledge, this is the first study in which electrolyte imbalance was significantly associated with the occurrence of pharmaceutical interventions. This finding reaffirms the need to correct serum electrolytes, especially given that such imbalances may be drug-related (e.g., diuretics, corticosteroids, laxatives, and angiotensin-converting enzyme inhibitors), to avoid negative clinical consequences such as muscle weakness, mental confusion, arrhythmias, ventricular fibrillation, and cardiac arrest. ${ }^{24}$

In this study, the prescription of 5 or more medications was significantly associated with the occurrence of pharmaceutical interventions. Given that hospital admission generally results in a significant increase in the number of drugs administered, ${ }^{25}$ often because of the need for concurrent treatment of acute and chronic disorders, ${ }^{26}$ inpatients are exposed to a greater risk of DRPs. That is why polypharmacy is frequently listed as a risk factor in DRP assessment tools that hospital pharmacists use to categorize the level of risk for inpatients and to prioritize patients for pharmaceutical care. ${ }^{27}$ Nevertheless, the elderly population (the majority 
of patients in our sample) frequently have many chronic conditions due to the aging process, so they are exposed to complex and long-term poly-pharmacotherapy. ${ }^{28}$

Similar to our results, data from 8713 admissions to a tertiary university hospital demonstrated that patients using systemic anti-infective agents had a $91 \%$ greater chance of experiencing a DRP. ${ }^{3}$ This result may be related to the evidence that success of antibacterial treatment depends on several pharmacokinetic and pharmacodynamic parameters ${ }^{29}$ which can be altered as a result of the patients' clinical condition and age (e.g., impaired renal function, very low body weight, and previous use of an antibiotic). A French study involving 1408 adult inpatients categorized medications according to second-level ATC codes and showed that the only drugs associated with medication error were antithrombotic agents (B01), antibacterial agents for systemic use (J01), psycholeptics (N05), blood substitutes and perfusion solutions (B05), and analgesics (N02). ${ }^{12}$

One limitation of our study is that the pharmaceutical interventions included in the analysis occurred on any day of the hospital stay, and thus might not necessarily have been related to medications prescribed within 24 hours after admission. Furthermore, we did not investigate clinical conditions or classes of medications commonly identified as risk factors for ADEs (e.g., cognitive decline, antihypertensive agents, diuretics, and nonsteroidal anti-inflammatory drugs), ${ }^{30}$ because of a lack of information in the patients' medical record or low prescription rates. The small sample size and the inclusion of patients from only 1 ward might have reduced the generalizability of the results. Another limitation is that non-patient-related factors were not evaluated. Clinical decision-making is a highly complex and dynamic process influenced by the knowledge, skills, attitudes, and context of the clinician. ${ }^{31}$ Different pharmacists may make different decisions based on the same data and may have different thresholds for intervening. We also did not evaluate whether the pharmaceutical interventions led to any changes in clinical outcomes. However, in this ward, clinical pharmacists perform thorough follow-up of all inpatients, from admission to discharge, and were highly experienced in providing pharmaceutical care. We believe that the assumption that all pharmaceutical interventions performed were justified is likely true, because the pharmacists have developed their careers in the clinical setting, have obtained professional certifications of their knowledge, and had a standard of evidence-based thinking.

Although older age, female sex, and renal impairment are frequently cited as being associated with ADEs in adult inpatients, ${ }^{30}$ we did not find them to be statistically associated with the occurrence of at least 1 pharmaceutical intervention. Interestingly, the ORs for older age and female sex revealed protection, not risk. We do not recommend that clinical pharmacists exclude the assessment of renal function from daily patient analysis, as this factor affects the pharmacodynamic and pharmacokinetic parameters of many drugs. ${ }^{32}$

We suggest future research with larger numbers of participants, longer periods of study, and more robust methods for finding the predictors of pharmaceutical interventions, with the purpose of exploring individual differences among pharmacists that may influence pharmaceutical interventions. There is a need to prioritize pharmacy services, which could be done through early identification of inpatients' characteristics at admission. Such identification could be related to pharmaceutical interventions and thus lead to the optimization of human and financial resources, as well as improved quality of care and patient safety.

\section{CONCLUSION}

In this study, 3 patient-level factors at the time of admission were associated with higher odds of a patient receiving at least 1 pharmaceutical intervention during the hospital stay: electrolyte imbalance, prescription of at least 5 medications, and prescription of at least 1 antibacterial for systemic use.

\section{References}

1. Silva C, Ramalho C, Luz I, Monteiro J, Fresco P. Drug-related problems in institutionalized, polymedicated elderly patients: opportunities for pharmacist intervention. Int J Clin Pharm. 2015;37(2):327-34.

2. PCNE classification system for drug-related problems. Version 9.00. Pharmaceutical Care Network Europe; revised 2019 [cited 2019 November]. Available from: https://www.pcne.org/upload/files/334 PCNE_classification_V9-0.pdf

3. Urbina O, Ferrández O, Grau S, Luque S, Mojal S, Marin-Casino M, et al. Design of a score to identify hospitalized patients at risk of drugrelated problems. Pharmacoepidemiol Drug Saf. 2014;23(9):923-32.

4. Oscanoa TJ, Lizaraso F, Carvajal A. Hospital admissions due to adverse drugreactionsin theelderly. A meta-analysis.EurJClin Pharmacol.2017; 73(6):759-70.

5. Meier F, Maas R, Sonst A, Patapovas A, Müller F, Plank-Kiegele B, et al. Adverse drug events in patients admitted to an emergency department: an analysis of direct costs. Pharmacoepidemiol Drug Saf. 2015;24(2):176-86.

6. Riaz M, Brown J. Association of adverse drug events with hospitalization outcomes and costs in older adults in the USA using the nationwide readmissions database. Pharm Med. 2019;33(4):321-9.

7. The report of the Short Life Working Group on reducing medicationrelated harm. Department of Health \& Social Care (UK); 2018 [cited 2020 May 11]. Available from: https://assets.publishing.service.gov.uk/ government/uploads/system/uploads/attachment_data/file/683430/ short-life-working-group-report-on-medication-errors.pdf

8. Walsh E, Hansen C, Sahm L, Kearney P, Doherty E, Bradley C. Economic impact of medication error: a systematic review. Pharmacoepidemiol Drug Saf. 2017;26(5):481-97.

9. Sutherland A, Canobbio M, Clarke J, Randall M, Skelland T, Weston E. Incidence and prevalence of intravenous medication errors in the UK: a systematic review. Eur J Hosp Pharm. 2020;27(1):3-8.

10. Alomar M. Factors affecting the development of adverse drug reactions. Saudi Pharm J. 2014;22(2):83-94.

11. Falconer N, Nand S, Liow D, Jackson A, Seddon M. Development of an electronic patient prioritization tool for clinical pharmacist interventions. Am J Health Syst Pharm. 2014;71(4):311-20. 
12. Nguyen TL, Leguelinel-Blache G, Kinowski JM, Roux-Marson C, Rougier M, Spence J, et al. Improving medication safety: development and impact of a multivariate model-based strategy to target high-risk patients. PLoS One. 2017;12(2):e0171995.

13. Zopf Y, Rabe C, Neubert A, Hahn N, Dormann H. Risk factors associated with adverse drug reactions following hospital admission. Drug Saf. 2008;31(9):789-98.

14. Krähenbühl-Melcher A, Schlienger R, Lampert M, Hascke M, Drewe J, Krähenbühl S . Drug-related problems in hospitals: a review of the recent literature. Drug Saf. 2007;30(5):379-407.

15. Levey AS, Stevens LA, Schmid CH, Zhang Y, Castro A, Feldman H, et al.; CKD-EPI (Chronic Kidney Disease Epidemiology Collaboration). A new equation to estimate glomerular filtration rate. Ann Intern Med. 2009;150(9):604-12.

16. ATC/DDD index 2019. WHO Collaborating Centre for Drugs Statistics Methodology; 2019 [cited 2019 Oct]. Available from: https:// www.whocc.no/atc_ddd_index

17. Charlson ME, Pompei P, Ales KL, MacKenzie CR. A new method of classifying prognostic comorbidity in longitudinal studies: development and validation. J Chronic Dis. 1987;40(5):373-83.

18. Viana S, Arantes T, Ribeiro S. Interventions of the clinical pharmacist in an Intermediate Care Unit for elderly patients. Einstein. 2017;15(3):283-8. Article in Portuguese and English.

19. Brulhart MI, Wermeille JP. Multidisciplinary medication review: evaluation of a pharmaceutical care model for nursing homes. Int J Clin Pharm. 2011;33(3):549-57.

20. Westberg SM, Yarbrough A, Weinhandl ED, Adam TJ, Brummel AR, Reidt SL, et al. Drug therapy problem severity following hospitalization and association with 30-day clinical outcomes. Ann Pharmacother. 2018;52(12):1195-203.

21. Cuentro V, Andrade M, Gerlack L, Bós A, Silva M, Oliveira A. Prescrições medicamentosas de pacientes atendidos no ambulatório de geriatria de um hospital universitário: estudo transversal descritivo [Drug prescriptions of patients treated in a geriatric outpatient ward of a university hospital: a descriptive cross-sectional study]. Cien Saude Colet. 2014;19(8):3355-64. Article in Portuguese.

22. Ribeiro S, Pinto J, Ribeiro J, Félix M, Barroso S, Oliveira L, et al. Pain management at inpatient wards of a university hospital. Rev Bras Anestesiol. 2012;62(5):599-611.

23. Osemeke N, Hart O, Cosmas N, Ohumagho I. Geriatric prescription in a Nigerian tertiary hospital. J Basic Clin Pharm. 2016;8(1):20-4.

24. Walker R, Whittlesea C. Laboratory data. In: Walker R, Whittlesea C, editors. Clinical pharmacy and therapeutics. 3rd ed. Churchill Livingstone; 2003. p. 77-80.
25. Hayashi Y, Godai A, Yamada M, Yoshikura N, Harada N, Koumura $A$, et al. Reduction in the numbers of drugs administered to elderly in-patients with polypharmacy by a multidisciplinary review of medication using electronic medical records. Geriatr Gerontol Int. 2017; 17(4):653-8.

26. O’Connor M, Gallagher P, Byrne S, O’Mahony D. Adverse drug reactions in older patients during hospitalisation: are they predictable? Age Ageing. 2012;41(6):771-6.

27. Alshakrah MA, Steinke DT, Lewis PJ. Patient prioritization for pharmaceutical care in hospital: a systematic review of assessment tools. Res Social Adm Pharm. 2019;15(6):767-79.

28. Salive ME. Multimorbidity in older adults. Epidemiol Rev. 2013;35(1): 75-83.

29. Levison M, Levison J. Pharmacokinetics and pharmacodynamics of antibacterial agents. Infect Dis Clin North Am. 2009;23(4):791-815.

30. Mihajlovic S, Gauthier J, MacDonald E. Patient characteristics associated with adverse drug events in hospital: an overview of reviews. Can J Hosp Pharm. 2016;69(4):294-300.

31. Abuzour AS, Lewis PJ, Tully MP. A qualitative study exploring how pharmacist and nurse independent prescribers make clinical decisions. J Adv Nurs. 2018;74(1):65-74.

32. Conforti A, Costantini D, Zanetti F, Moretti U, Grezzana M, Leone R. Adverse drug reactions in older patients: an Italian observational prospective hospital study. Drug Healthc Patient Saf. 2012;4:75-80.

Debora Bernardes Francisco, BPharm, is a Resident with the Clinical Pharmacy Residency Program, School of Pharmaceutical Sciences, University of São Paulo, São Paulo, Brazil.

Karine Dal Paz, BPharm, MSc, is a Pharmacist and Head of the Clinical Pharmacy Service, University Hospital, University of São Paulo, São Paulo, Brazil.

Thiago Vinicius Nadaleto Didone, BPharm, MSc, is a PhD student with the Department of Clinical and Experimental Oncology, Paulista School of Medicine, Federal University of São Paulo, São Paulo, Brazil.

Competing interests: None declared.

Address correspondence to:

Thiago Vinicius Nadaleto Didone

R Dr Diogo de Faria 824

Vila Clementino

São Paulo/SP, Brasil 04037-002

email: tdidone@gmail.com

Funding: None received. 